\title{
Corrigendum: From Resistance to Sensitivity: Insights and Implications of Biphasic Modulation of Autophagy by Sunitinib
}

\begin{abstract}
Amal Kamal Abdel-Aziz ${ }^{1,2}$, Ashraf B. Abdel-Naim², Samia Shouman ${ }^{3}$, Saverio Minucci ${ }^{1,4 *}$ and Mohamed Elgendy ${ }^{5 *}$

${ }^{1}$ Department of Experimental Oncology, European Institute of Oncology, Milan, Italy, ${ }^{2}$ Department of Pharmacology and Toxicology, Faculty of Pharmacy, Ain Shams University, Cairo, Egypt, ${ }^{3}$ Cancer Biology Department, National Cancer Institute, Cairo University, Cairo, Egypt, ${ }^{4}$ Department of Biosciences, University of Milan, Milan, Italy, ${ }^{5}$ Max F. Perutz Laboratories, Department of Microbiology and Immunobiology, University of Vienna, Vienna, Austria
\end{abstract}

Keywords: autophagy, cancer, Mcl-1, mTOR, resistance, Sunitinib

\section{A corrigendum on}

From Resistance to Sensitivity: Insights and Implications of Biphasic Modulation of Autophagy by Sunitinib

by Abdel-Aziz, A. K., Abdel-Naim, A. B., Shouman, S., Minucci, S., and Elgendy, M. (2017). Front. Pharmacol. 8:718. doi: 10.3389/fphar.2017.00718

Edited and reviewed by: Amit K. Tiwari,

University of Toledo, United States

*Correspondence:

Saverio Minucci

saverio.minucci@ieo.it

Mohamed Elgendy

mohamed.elgendy@univie.ac.at

Specialty section

This article was submitted to Pharmacology of Anti-Cancer Drugs,

a section of the journal

Frontiers in Pharmacology

Received: 05 January 2018

Accepted: 30 January 2018

Published: 12 February 2018

Citation:

Abdel-Aziz AK, Abdel-Naim AB, Shouman S, Minucci S and Elgendy M (2018) Corrigendum: From Resistance to Sensitivity: Insights and Implications of Biphasic Modulation of Autophagy by Sunitinib. Front. Pharmacol. 9:101. doi: 10.3389/fphar.2018.00101
In the original article, acknowledgment of funding by the Mahlke-Obermann Stiftung and the European Union's Seventh Framework Programme for research, technological development and demonstration under grant agreement no. 609431/INDICAR (Interdisciplinary Cancer Research) Postdoctoral Fellowship Programme of the University of Vienna to ME was missing. The authors apologize for this oversight. This error does not change the scientific conclusions of the article in any way.

The original article has been updated.

\section{ACKNOWLEDGMENTS}

Work in SM's lab is supported by AIRC, FIRC, CNR (Epigen), and Horizon 2020 grants. AKA has been awarded a fellowship by AIRC. ME received funding from the Mahlke-Obermann Stiftung and the European Union's Seventh Framework Programme for research, technological development and demonstration under grant agreement no. 609431/INDICAR (Interdisciplinary Cancer Research) Postdoctoral Fellowship Programme of the University of Vienna.

Conflict of Interest Statement: The authors declare that the research was conducted in the absence of any commercial or financial relationships that could be construed as a potential conflict of interest.

Copyright (C) 2018 Abdel-Aziz, Abdel-Naim, Shouman, Minucci and Elgendy. This is an open-access article distributed under the terms of the Creative Commons Attribution License (CC BY). The use, distribution or reproduction in other forums is permitted, provided the original author(s) and the copyright owner are credited and that the original publication in this journal is cited, in accordance with accepted academic practice. No use, distribution or reproduction is permitted which does not comply with these terms 